\title{
Birth Injuries in Neonates at a University Teaching Hospital in Cameroon: Epidemiological, Clinical and Therapeutic Aspects
}

\author{
E. M. Mah'1,2*, P. Foumane1,2, D. H. Ngwanou2, S. Nguefack ${ }^{1,2}$, A. Chiabi1,2, J. S. Dobit ${ }^{1,2}$, H. Siyou1, \\ J. B. Bogne ${ }^{1,2}$, E. Mbonda',2, Fru Angwafo III ${ }^{1,2}$ \\ ${ }^{1}$ Yaounde Gyneco-Obstetric and Pediatric Hospital, Yaounde, Cameroon \\ ${ }^{2}$ Faculty of Medicine and Biomedical Sciences, University of Yaounde I, Yaounde, Cameroon \\ Email: *aminevelyn@yahoo.co.uk
}

How to cite this paper: Mah, E.M., Foumane, P., Ngwanou, D.H., Nguefack, S., Chiabi, A., Dobit, J.S., Siyou, H., Bogne, J.B., Mbonda, E. and Angwafo III, F. (2017) Birth Injuries in Neonates at a University Teaching Hospital in Cameroon: Epidemiological, Clinical and Therapeutic Aspects. Open Journal of Pediatrics, 7, 51-58.

https://doi.org/10.4236/ojped.2017.71008

Received: February 22, 2017

Accepted: March 27, 2017

Published: March 30, 2017

Copyright $\odot 2017$ by authors and Scientific Research Publishing Inc. This work is licensed under the Creative Commons Attribution International License (CC BY 4.0).

http://creativecommons.org/licenses/by/4.0/

(c) (i) Open Access

\begin{abstract}
Background: Statistics on birth injuries in Cameroon are scarce, despite its frequency in postnatal consultations; we sort to find its prevalence and contributing factors, the different clinical presentations and treatment methods. Methodology: This was a retrospective, descriptive study. Data on maternal characteristics, neonatal factors, the place of birth and qualification of birth attendant, age at diagnosis, clinical presentation and management were considered. Results: Among the 14,284 newborns that were consulted from January 2003 to February 2014, 263 (1.84\%) had birth injuries. The average age at diagnosis was 12 days. The contributing factors were: advanced maternal age, macrosomia, vaginal and instrumental delivery. Birth attendants were mostly nurses and the health center was the place of birth for $57.4 \%$ of patients. The main clinical presentations were: obstetric brachial plexus palsy (70.6\%), fracture of the clavicle $(22.5 \%)$ and fracture of the humerus (4.80\%). Physiotherapy and orthopedic treatment were methods used with favorable outcome. Conclusion: The frequency of birth injury is relatively high in our context. The diagnosis is late, birth attendants need to be trained and systematic examination of all newborns in delivery room encouraged.
\end{abstract}

\section{Keywords}

Birth Injury, Newborn, Yaoundé

\section{Introduction}

Injuries to the neonate that result from mechanical forces (compression, trac- 
tion, cuts etc.) during the birth process are categorized as birth trauma [1]. The majority of birth injuries are minor and often not reported; but birth injuries may be so severe as to be fatal or leave the child with a permanent disability.

In the USA, birth injuries occur in about 20 - 30 per 1000 births [2]. In Africa, statistics on birth injuries are not easy to come by; however, studies carried out in Mali and Morocco revealed frequencies of $0.68 \%$ and $0.26 \%$ respectively and a survey on rural Egyptian birth attendants in different regions revealed the prevalence of birth injuries to vary from7\% to $17 \%$ [3] [4] [5]. The main risk factors are fetal weight at birth, instrumental delivery, fetal presentation, parity and maternal age [6] [7] [8] [9]. Treatment involves immobilization for bone injuries, rehabilitation and reconstructive surgery [10].

Training of midwives in Cameroon was suspended for over twenty years and during which time; traditional birth attendants without any formal medical training were involved in the care of women during childbirth in the community. For this reason personnel posted to most of the delivery rooms and maternities are nurses with basic knowledge on obstetrics and very little on essential newborn care. It is common to see babies with birth injuries during routine neonatal consultation but information on its prevalence, clinical presentation, diagnostic bottlenecks and treatment modalities in a low resource context as ours are scarce, reason why we carried out this study with the aim of describing the epidemiological, clinical and therapeutic aspects of birth injuries in newborns seen at a reference hospital in Yaoundé, in order to suggest preventive, diagnostic and therapeutic measures.

\section{Patients and Method}

We conducted a descriptive study with retrospective collection of data over an eleven-year period from 1 March 2003 to 28 February 2014. We carried out a comprehensive survey of all neonates with birth injuries received at the Yaoundé Gyneco-Obstetric and Pediatric Hospital (YGOPH) during the study period. Registers from the neonatal unit, pediatric outpatient, physiotherapy and pediatric surgery units were consulted to retrieve the names of all neonates diagnosed with birth injury. Then the medical files were collected from the archives of the different units to obtain relevant information on the neonates. Minor injuries such as caput succedaneum, scratches and bruises, together with files that could not be exploited were excluded. Information concerning the mothers retrieved from the files included: age, height, medical and obstetric history, age of pregnancy, qualification of the birth attendant; and in the neonate: Place of birth, birth weight, age, age at diagnosis, functional signs, diagnosis, para clinical investigation, treatment and outcome. We defined macrosomia as birth weight $>$ 4000 g. The diagnosis was made after clinical examination by the pediatrician and confirmed with imagery (plain x-ray essentially) when possible.

Data analysis was done using the software Epi-Info ${ }^{\mathrm{TM}}$ version 3.5.4, and Mi- 
crosoft Excel 2007.

\section{Ethical Considerations}

Ethical clearance was obtained from the Yaounde Gyneco-Obstetric and Pediatric Hospital Institutional Committee for Research and information from patient files was confidential and used only for this study.

\section{Results}

During the study period, 14,284 newborns were received and 263 had birth injuries, giving a hospital frequency of $1.84 \%$.

\subsection{Socio Demographic Data}

\section{- Characteristics of Neonates}

Almost all the babies (84\%) were term babies. The male sex was most represented, with $55 \%$ of the cases and a sex ratio of 1.22 .

The most represented age group was the 0 - 10 days group. Although most of the babies (56.7\%) had normal weight, $41.2 \%$ were macrosomic (Table 1 ). Many neonates $(50.8 \%)$ came from their homes; most of the babies $(57.4 \%)$ were born in health centers. and only 1 child was born at home (Table 2).

\section{- Maternal characteristics}

The mean maternal age was $28.14 \pm 5.27$ years and the mean maternal height was $163.17 \pm 5.60 \mathrm{~cm}$. The mothers of newborns with birth injuries were mostly paucipara, representing $59.9 \%$ of the cases (Table 3 ). Only $2.7 \%$ of mothers had diabetes and $6.4 \%$ were obese.

The delivery of neonates with injuries was per vaginal in 182 (97.3\%) cases and there was the use of instruments (mostly forceps) in $5.3 \%$ of the cases.

\subsection{Diagnosis}

Only $8.6 \%$ of neonates with birth injuries were diagnosed on the first day of life, against $13.4 \%$ within 48 hours and $78 \%$ after the $2^{\text {nd }}$ day of life. The mean age at diagnosis was 12 days (Table 1 ).

Table 1. Characteristics of neonates with births injuries.

\begin{tabular}{ccc}
\hline Variables & Number of cases & Percentage (\%) \\
\hline$<2500$ & Birth weight $(\mathrm{g})$ & \\
$2500-4000$ & 5 & 2.1 \\
$>4000$ & 148 & 56.7 \\
\hline $0-10$ & 110 & 41.2 \\
\hline $10-20$ & Age at diagnosis (days) & 51.9 \\
$20-28$ & 137 & 22.5 \\
Total & 60 & 25.6 \\
\hline
\end{tabular}


Table 2. The distribution of neonates with birth injuries in relation to place of birth and qualification of birth attendant.

\begin{tabular}{ccc}
\hline Variable & Number of cases (N) & Percentage (\%) \\
\hline Place of birth & 1 & 0.5 \\
Home & 151 & 57.4 \\
Health center & 4 & 1.6 \\
Sub divisional hospital ${ }^{*}$ & 43 & 16.4 \\
YGOPH & 64 & 24.3 \\
Other Hospitals ${ }^{* *}$ & & \\
\hline Qualification of birth attendant $^{*}$ Gynecologist-Obstetrician & 22 & 8.6 \\
General practitioner & 4 & 1.6 \\
Midwife & 76 & 28.9 \\
Nurse & 117 & 44.3 \\
Others & 44 & 16.6 \\
\hline Total & 263 & 100.0 \\
\hline
\end{tabular}

${ }^{*}$ Sub-divisional/Health Center: The first level of care on the health pyramid. ${ }^{*}$ Other reference hospitals, private and para public hospitals, district and regional hospitals. YGOPH: tertiary/reference hospital for mother and child.

Table 3. Characteristics of mothers of neonates with birth injury.

\begin{tabular}{ccc}
\hline Variables & Number of cases (N) & Percentage(\%) \\
\hline Age (years) & 21 & 8.0 \\
\hline$<20$ & 159 & 60.4 \\
$20-30$ & 80 & 30.6 \\
$>30-40$ & 3 & 1.0 \\
$>40$ & & \\
\hline Height (cm) & 4 & 1.6 \\
$<150$ & 188 & 71.1 \\
$\geq 150$ & 71 & 27.3 \\
\hline Not mentioned & & 28.9 \\
\hline Parity & 76 & 59.9 \\
\hline Primipara & 158 & 11.2 \\
Paucipara & 29 & 100.0 \\
Multipara & 263 & \\
Total & &
\end{tabular}

The most frequent birth injury was brachial nerve palsy representing $70.6 \%$ of all birth injuries, followed by fracture of the clavicle (22.5\%) (Table 4).

The brachial plexus palsies were all partial (mostly Erb's palsies) and the right side was most affected. Ten patients presented with two injuries and the most common association was brachial plexus palsy and fracture of the clavicle.

Plain radiography was the most frequently performed investigation, in $74.9 \%$ of cases. 
Table 4. Clinical presentation of birth injuries.

\begin{tabular}{ccc}
\hline Diagnosis & Number of cases (N) & Percentage (\%) \\
\hline Obstetric brachial plexus palsy & 186 & 70.6 \\
Fracture of the clavicle & 59 & 22.5 \\
Fracture of the humeral shaft & 13 & 4.8 \\
Fracture of the Femoral shaft & 8 & 3.2 \\
Elbow dislocation & 1 & 0.5 \\
Fracture of the forearm & 2 & 1.0 \\
Shoulder dislocation & 1 & 0.5 \\
Sterno-clavicular joint dislocation & 1 & 0.5 \\
\hline
\end{tabular}

\subsection{Management}

The management of brachial plexus palsy involved physiotherapy with four modalities: electro stimulation, splint, massage and passive mobilization.

Fractures and dislocations were mainly treated by reduction and casting, combined with traction for femoral fractures. Abstention for cases of fractures diagnosed late with an already formed callus. Bone consolidation occurred within an average period of 21 days for fractures and complete remission of dislocations within 10 days.

\section{Discussion}

The major weakness of this study was the fact that due to its retrospective design and the long study period, the quality of data collected could be affected as this could vary with time. The study involved only patients with birth injuries, and this made it difficult for the risk factors to be brought out. However there were some features that were common to babies with birth injuries.

The aim of this study was to find the prevalence of birth injury in neonates seen in our health facility, study the contributing factors, the different clinical presentations and treatment methods used.

The frequency of birth injuries varies considerably in the literature. Authors in Mali and Morocco found incidence of $0.68 \%$ and $0.26 \%$ respectively [2] [3] both lower than our frequency of $1.84 \%$. This difference could be explained by the different lengths of the study periods; their studies lasted 12 and 16 months respectively against 11 years for our study. The patients in our sample came from different hospitals and health centers in Yaoundé and beyond.

The male sex was more represented in our population similar to reports by other authors [3] [4] [5] but the reasons for this are not clear. Almost all the babies in our series were term babies.

The mean age at diagnosis was 12 days. Nandiolo et al. in Cote d'Ivoire [11] reported a mean age of 14 days, similar to the findings of Moussa in Mali [4]. This delay in diagnosis reflects the absence or the poor quality of routine examination of the neonates in the delivery room in Africa in general and Cameroon in particular. Newly born babies must be thoroughly examined in the deli- 
very room to appreciate the adaptation to extra uterine life, malformation and birth injuries. It is recommended that the mother and child should be under observation for at least 72 hours after birth but this is not often respected. Most women go home immediately after childbirth because of financial constrains and sometimes lack of space in the maternity. Early discharged from the maternity immediately after delivery could also be a contributing factor for late diagnosis.

As described in literature birth injuries occur more in big term babies. Macrosomia was not frequent in other series [3] [4] [13], but it was found to be associated with birth injury in this series, with $41.7 \%$ of our patients being macrosomes. The difference could be explained by the fact that the mothers in our series were taller with heights above $1.63 \mathrm{~m}$.

The mean maternal age was 28.14 years, close to the findings of Chou Yeng et al. in China [12] who found an average maternal age of about 30 years. Although advanced maternal age has been shown to be associated with large babies [12] [14]; most of the mothers in our series were in the normal child bearing age. The mothers of $59.9 \%$ of neonates with birth injuries in our series were mostly paucipara, and pauciparity has been reported as a risk factor for birth injury by several authors [2] [3] [4].

Per vaginal delivery was the main mode of delivery in $97.3 \%$ of cases in our series comparable to the results of Nandiolo et al. in Cote d'Ivoire [11] and Moussa in Mali [4].

Moussa reported that health centers were the most frequent site of delivery in $34.3 \%$ of cases with birth injury [4] lower than our finding of $42.8 \%$. In the health centers, the birth attendants are mainly nurses and nursing aids that compared to midwives, have less experience and training in obstetrics. The consequences of such a situation is that complicated labor with dystocia is not recognized on time and most often not referred for adequate management. This reflects the low rate $(2 \%)$ of $\mathrm{C}$-section in Cameroon. This could also be a factor contributing to the occurrence of birth injuries in this series.

The forceps was the most frequently used instrument for delivery in the series of other authors [4] [15] in proportions higher than in our series. This could be because, the birth attendants in our study were nurses and only about $8.6 \%$ were obstetricians trained to use forceps for delivery and the fact that the majority of the deliveries in our series were conducted in health centers, where the equipment was probably not available.

Studies in Guinea and Mali revealed that most deliveries were assisted by midwives [4] [13], contrary to our findings where the birth attendants were nurses. The difference could be due to the fact that midwives are a minority in Cameroon given that training schools for midwives were closed down for the past twenty years and nurses make up the work force for most maternities.

The frequency of Obstetric brachial plexus palsy varies markedly in the literature; Nandiolo et al. in Cote d'Ivoire [11] found 38\%, Moussa in Mali [4] reported 38.9\%, Khouja in Morocco [3] 15.2\% and Camus et al. en France [10] found 1.09 per 1000 births. These results are lower the $70.6 \%$ rate in our series. 
The difference in recruitment sites and the large number of macrosomic neonates could justify these discrepancies.

Fracture of the clavicle was the second most common injury in our series (22.5\%) comparable to those of the authors in Mali, Morocco and Guinea [3] [4] [13]. However, Nandiolo et al. [11] reported higher rates reaching 66\% while Borna et al. in Iran [16] reported that $40 \%$ of birth injuries were fractures of the clavicle. Fracture of the humerus was not very common in our series $(4.8 \%)$, lower than the $9.1 \%$ of Khouja in Morocco [3]. This difference could be explained by the differences in the methodologies.

Plain radiography was the most performed investigation. Moussa in Mali [4] and other African authors used radiography as the main means of investigation [1] [11] [17]. This could be due to its availability and affordability.

Physiotherapy was the main therapeutic method used in our series as well as in those of Moussa in Mali [4] and Souna in Niger [18] due to the high proportion of partial brachial plexus palsy in our series. Orthopedic treatment was indicated in cases of dislocation and fractures with favorable outcomes as in the series of Moussa in Mali, Nandiolo et al. in Cote d'Ivoire and Souna et al. in Niger [4] [11] [18].

\section{Conclusion}

Birth attendants in most of our health facilities are mainly nurses. Birth injuries in neonates in our context remain relatively high and diagnosed many days after the mother and baby must have been discharged from the maternity. Midwives need to be trained and posted to maternities in our health facilities. There is a need for the reinforcement of routine examination of all babies at birth for early diagnosis and treatment of birth injuries and other neonatal problems.

\section{Acknowledgements}

This study was conducted with the valuable help of the staff of the nursing and archives services of the Yaoundé Gyneco-Obstetric and Pediatric Hospital.

\section{Financial Disclosure}

The authors have no financial relationships relevant to this article to disclose.

\section{References}

[1] Abubakar, A.M., Askegard-Giesmann, J.R. and Kenney, B.D. (2015) Birth Injury. http://www.globalhelp.org/publications/books/help_pedsurgeryafrica.35.pdf

[2] Sauber-Schatz, E., Markovic, N., Weiss, H., Bodnar, L., Wilson, J. and Pearlman, M.D. (2010) Descriptive Epidemiology of Birth Trauma in the United States in 2003. Paediatric and Perinatal Epidemiology, 24, 116-124. https://doi.org/10.1111/j.1365-3016.2009.01077.x

[3] Louay, K. (2013) Les traumatismes obstétricaux chez le nouveau-né (A propos de 33 cas). Thèse de doctorat en medicine, Faculté de médecine et de pharmacie Fès, Université Sidi Mohammed Ben Abdellah Maroc.

[4] Samaké, M. (2008) Traumatisme obstétrical du nouveau-né dans le service de chi- 
rurgie pédiatrique du CHU Gabriel Touré. Thèse de doctorat en medicine, Faculté de médecine, de pharmacie et d'odonto-stomatologie, Université de Bamako.

[5] Damstedt, G.L., Hussein, M.H., Winch, P.J., et al. (2008) Practices of Rural Egyptian Birth Attendants during the Antenatal, Intrapartum and Early Neonatal Period. Journal of Health, Population and Nutrition, 26, 36-45.

[6] Broux, C., Andrini, P., Douchin, S. and Eymeriaud, G. (2000) An Unrecognized Neonatal Emergency: Extensive Hematoma of the Scalp. La Presse Médicale, 29, 1451-1454.

[7] Ndiaye, O., Diouf, L., Sylla, A., Diallo, R. and Kuakuvi, N. (2001) Lésions traumatiques du nouveau-né après accouchement par forceps à la maternité de l'hôpital Abass Ndao. Dakar Medical, 46, 36-38.

[8] Linder, N., Linder, I., Fridman, E., Kouadio, F., Lubin, D., Merlob, P., et al. (2013) Birth Trauma-Risk Factors and Short-Term Neonatal Outcome. The Journal of Maternal-Fetal \& Neonatal Medicine, 26, 1491-1495.

[9] Ozdener, T., Engin-Ustun, Y., Aktulay, A., Turkcapar, F., Oguz, S., Yapar Eyi, G., et al. (2013) Clavicle Fracture: Its Incidence and Predisposing Factors in Term Uncomplicated Pregnancy. European Review for Medical and Pharmacological Sciences, $17,1269-1272$.

[10] Camus, M., Lefebvre, G., Veron, P. and Darbois, Y. (1987) Traumatismes obstétricaux du nouveau-né. Enquête rétrospective à propos de 20409 naissances. Journal de Gynécologie Obstétrique et Biologie de la Reproduction, 14, 1033-1043.

[11] Nandiolo, A., Manzan, S. and Bankole, S. (2012) Prise en charge des traumatismes obstétricaux. A propos de 148 cas. Revue Internationale des Sciences Médicales, 14, 136-140.

[12] Chou, Y., Tseng, T., Huang, H. and Wang, C. (2004) Clavicle Fracture in Newborns: A Retrospective Five-Year Analysis. Clinical Neonatology, 11, 9-13.

[13] Keita, M., Radji, M. and Doumbouya, N. (2003) Traumatismes d'origine Obstétricale. Fréquence et stratégies de prise en charge dans le service de chirurgie pédiatrique de l'hôpital national de Donka. en Guinée Konakry de Mars 2001 au Mars 2002. Archives de Pédiatrie, 12, 13-19.

[14] ROGER NTG (2013) Macrosomie foetale: Devenir maternel et néonatal précoce au Centre Hospitalier et Universitaire de Yaoundé et à l'hôpital Central de Yaoundé et à l'HCY. http://www.hsd-fmsb.org/index.php/hsd/thesis/view/97

[15] Alexander, J., Leveno, K., Hauth, J., Landon, M., Thom, E., Spong, Y., et al. (2006) Fetal Injury Associated with Cesarean Delivery. Obstetrics \& Gynecology, 108, 885890. https://doi.org/10.1097/01.AOG.0000237116.72011.f3

[16] Borna, H., Rad, M., Borna, S. and Mohseni, M. (2010) Incidence and Risk Factors for Birth Trauma in Iran. Taiwanese Journal of Obstetrics and Gynecology, 49, 170 173.

[17] Guermazi, M., Ghroubi, S., Mezghanni, M., Triki, F.E. and Elleuch, M.H. (2004) Suivi à long terme des épaules paralytiques obstétricales (à propos de 129 cas). Annales de Réadaptation et de Médecine, 47, 7-12.

[18] Souna B, Abarchi H, Hassanatou N. (2006) Les traumatismes obstétricaux des membres chez le nouveau-né: Aspects épidémiologiques, prise en charge, revue de la littérature (à propos de 7 cas colliges à Niamey). Revue Marocaine Chirurgie Orthopedique et Traumatologique, 28, 27-31. 
Submit or recommend next manuscript to SCIRP and we will provide best service for you:

Accepting pre-submission inquiries through Email, Facebook, LinkedIn, Twitter, etc. A wide selection of journals (inclusive of 9 subjects, more than 200 journals)

Providing 24-hour high-quality service

User-friendly online submission system

Fair and swift peer-review system

Efficient typesetting and proofreading procedure

Display of the result of downloads and visits, as well as the number of cited articles Maximum dissemination of your research work

Submit your manuscript at: http://papersubmission.scirp.org/

Or contact ojped@scirp.org 